\title{
Decreased collagen ratio type I/III in association with hemorrhoidal disease
}

\author{
Langenbach $M R^{1 *}$, Lisovets $R^{1}$, Varga-Szabo $D^{2}$ and Bonicke $L^{2}$ \\ ${ }^{1}$ Department of Surgery II, University of Witten/Herdecke, Helios St. Elisabeth Klinik Oberhausen, Oberhausen, Germany \\ ${ }^{2}$ Department of Surgery II, Universitatsklinikum Helios Wuppertal, University of Witten/Herdecke, Wuppertal, Germany
}

\begin{abstract}
Aim: Collagens are the most abundant macromolecules in extracellular matrices and naturally occur in the cutaneous extracellular matrix. Assuming, that collagen metabolism might be an important factor in the etiology of hemorrhoidal disease, we analyzed quality of collagen formation in the corpus cavernosum recti in patients with hemorrhoids degree III and IV in comparison to persons without.

Methods: Employing a case-control design, this study compared 71 patients with hemorrhoids with 20 controls free of hemorrhoidal disease. From January 2017 until December 2017 all patients scheduled for surgical therapy of their $\mathrm{III}^{\circ}$ or $\mathrm{IV}^{\circ}$ hemorrhoids were consecutively evaluated. The collagen I/III ratio served as parameter for the quality of collagen formation and was calculated using cross polarization spectroscopy.

Results: Type I collagen in the case group was significantly lower by about a half as compared to controls $(5.98 \pm 0.10$ vs $6.31 \pm 0.14$; $p<0.001)$. The collagen type I/ III ratio was highly variable but clearly lower in patients with hemorrhoidal disease than in controls $(1,31 \pm 0,43$ vs $2,31 \pm 1,07$; $p<0.001)$. The percentage error of the collagen type I/III ratio measurements was as low as 33\% (median). Age and gender showed no association with collagen fibers Analysis of repeated measurements showed very good reproducibility, with a Pearson's correlation coefficient of 0.968 .
\end{abstract}

Conclusion: Patients with hemorrhoidal disease showed a significant disorder in collagen metabolism. Pathophysiological process of hemorrhoidal disease seems to be associated with this. It remains still unclear, whether the changes of collagen formation in hemorrhoidal tissue are caused by exogenous factors or hereditary reasons.

\section{Introduction}

The etiology of symptomatic hemorrhoids is still widely unknown [1]. Stelzner described them as a complex compound of arteriovenous links in the rectal mucosa with an interlace of unstriated muscles, elastic fibers and connective tissue [2]. This "corpus cavernosum recti" is an important component of the continence mechanism especially for fluid stools and gas [2]. Although the prevalence of hemorrhoidal disease ranges between $4.4 \%$ and $86 \%$ in normal population $[3,4]$, causes are still unknown. Some authors blame exogenous factors like constipation and abnormal bowel habits [1]. An increased maximum resting pressure in the anal region is the most consistently demonstrated physiological abnormality. This leads to the hypothesis, that hemorrhoids are a hyperplasia of the corpus cavernosum recti caused by the high contraction of the internal anal sphincter [5]. On the other hand epidemiological data and histopathological findings support the hypothesis that reduced stability of the connective tissue can be blamed for the incidence of symptomatic hemorrhoids [6].

Collagens are the majority of macromolecules in extracellular matrices and naturally occur in the cutaneous extracellular matrix. Thus, mutations in human collagen genes can cause different connective tissue diseases and disturbance of macromolecular skin architecture [7]. For example, type IV Ehlers-Danlos (EDS type IV) syndrome is a collagenopathy characterized by vascular dissection or rupture, with patients exhibiting thin translucent skin and easy bruising [8]. Diagnosis is generally based on clinical findings and confirmed by the identification of a causative mutation in COL3A1 [9]. Furthermore, biochemical studies from cultured fibroblasts of EDS type IV-affected individuals show that structural abnormalities disturb pro-collagen III synthesis and cause intracellular retention and reduced secretion [10]. In this case specific collagen network staining of skin sections could be a rapid procedure for a clinical diagnosis [11]. Although there are at least 14 different types of collagen, type I and III are the two predominant types implicated in patients with connective tissue disorders, like in diverticulosis $[12,13]$. Type I collagen is composed of rigid fibrils and is the predominant type found in the body $[14,15]$. The type III collagen is thinner and generally regarded as immature and weak $[15,16]$. The typical ration of type I to III collagen is four to one [17]. For example, in hernia formation and aortic dissection collagen defects with a higher rate of elastic type III collagen, have been found $[18,19]$. In several studies it is described that collagen crosslinking is also increased in diverticulosis caused by proliferation of type III collagen. This collagen crosslinking increases with age, causing the tissue to become more rigid, resulting in the characteristic diverticular outpouching with increased intraluminal pressure $[13,15]$.

Focusing on the etiology of hemorrhoids there are studies showing that disintegration of muscular and elastic components might lead to a distal shift of the vascular padding [20]. Anatomic studies by Lierse showed that dilated hemorrhoidal vessels and the surrounding muscle

*Correspondence to: Mike $\mathrm{R}$ Langenbach, Klinik für Allgemein-/ Viszeralchirurgie und Koloproktologie, Helios St. Elisabeth Klinik, Josefstr, Oberhausen, Germany, E-mail: mike-ralf.langenbach@helios-gesundheit.de

Received: September 03, 2018; Accepted: September 14, 2018; Published: September 17, 2018 
fibers lie within a lattice of collagen and elastic fibers [21]. Degradation processes of this matrix, especially of the protein elastin during ageing were described to be a decisive pathway in the development of hemorrhoidal disease [21]. Elastic fibers in hemorrhoidal tissue are linked to collagen fibers. The elastic fibers are responsible for the elasticity; the collagen fibers are responsible for the tensile strength [6,21]. Assuming, that collagen metabolism might be an important factor in the etiology of hemorrhoidal disease, we analyzed the quality of collagen formation in the corpus cavernosum recti in patients with hemorrhoids degree III and IV in comparison to persons without.

\section{Methods}

Patients: Employing a case-control design, this study compared patients with hemorrhoids with controls free of hemorrhoidal disease. From January 2017 until December 2017 all patients scheduled for surgical therapy of their $\mathrm{III}^{\circ}$ or $\mathrm{IV}^{\circ}$ hemorrhoids were consecutively evaluated. All cases underwent a Milligan-Morgan hemorrhoidectomy. Specimens of these patients were collected and fixed in 10\% formalin and immediately embedded in paraffin for later analysis. As the control group we took 21 patients who had an amputation of the rectum because of malignancy. They did not suffer from hemorrhoidal disease, neither in present nor in past. The specimens from the controls were also collected and fixed in $10 \%$ formalin after the procedure and got immediately embedded in paraffin. All specimens were taken from the same anatomical region. All patients gave informed consent, that the specimen could be used.

Collagen type I/III ratio: Using cross polarization microscopy the quality of collagen was analyzed by the collagen type I/III ratio. The specimen was sliced into five-micrometer sections and were stained one hour in Picrosirius solution $\left(0,1 \%\right.$ solution of Sirius Red $\mathrm{F}_{3} \mathrm{BA}$ in saturated aqueous picric acid, $\mathrm{pH} 2$ ). The sections were washed afterwards for two minutes in $0.01 \mathrm{~N}$ HCL. Dehydration followed. Then the section was cleared and mounted in synthetic resin. Thicker collagen type I fibres were stained in red-orange shades, whereas thinner collagen type III appeared as pale-green shades. For each sample, 10 regions within the interface $(400 \mathrm{x}$, area $50 \mathrm{x} 50 \mu \mathrm{m})$ were captured by a digital camera (Olympus C-3030, Hamburg, Germany). Using a digital image analyzing software (Image-Pro Plus, media Cybernetics, Silver Spring, Maryland, USA) the collagen I/III ratios were obtained.

In order to verify the reproducibility of measurements, 10 specimens were randomly selected for a second measurement. This was performed by repeating the same analytical methods on another slice of the specimen without knowledge of the initial measurement results.

Statistical analysis: Both groups were compared with regard to demographic variables and collagen measurements. As collagen concentrations followed a highly skewed distribution, the base-10 logarithms of the values were calculated to meet the assumptions of parametric statistical testing. Continuous data was analyzed by Student's $\mathrm{t}$ test, while proportions were compared between groups by Fisher's exact test. $P$ values of less than 0.05 were considered significant. Furthermore, the potential influence of demographic variables on collagen results was examined. Because obesity was obviously associated with the type I/III collagen ratio, analyses were stratified for obese and non-obese patients.

Reproducibility of collagen measurements was quantified by calculating the difference between first and second measurement for the type I/III collagen ratio. The percentage error of measurements was obtained by dividing the absolute differences by the first measured value. In addition, Pearson's coefficient of correlation was calculated.

\section{Results}

There were 71 cases and 20 controls with an about even gender distribution within each group. On average, patients with hemorrhoidal disease were 14 years younger than control group patients (Table 1). Accordingly, some comorbidities were less prevalent among cases than among controls. In spite of the malignancies in the control group, the body mass index (BMI) was not significantly different between both groups.

The percentage error of the collagen type I/III ratio measurements was as low as $33 \%$ (median). Analysis of repeated measurements showed very good reproducibility, with a Pearson's correlation coefficient of 0.968 .

Type I collagen in the case group was lower by about a half as compared to controls (Table 2). The collagen type I/III ratio was highly variable but clearly lower in patients with hemorrhoidal disease than in controls (Figure 1). Collagen III was also slightly higher in cases than in controls, but significance was only seen after log-transformation of data, because a few control patients had very high values.

In the analysis of potentially modifying variables (Table 3 ), age and gender showed no association with collagen fibers. However, obese patients had a significantly higher collagen type I/III ratio as compared to patients without obesity. Therefore, analyses were repeated for both subgroups of obese and non-obese patients. In both subgroups, the main findings could be confirmed (Table 4). Patients with hemorrhoids had less collagen I, more collagen III, and a lower collagen type I/III ratio.

Table 1. Demographic characteristics and comorbidities of cases and controls. Data are means with standard deviations unless or counts and percentages. Data on height and weight were missing for 3 cases

\begin{tabular}{|c|c|c|c|}
\hline & Cases $(\mathbf{n}=\mathbf{7 1})$ & Controls $(\mathbf{n}=\mathbf{2 0})$ & $\boldsymbol{P}$ value \\
\hline Age in years & $52.0(9.4)$ & $65.8(12.4)$ & $<0.001$ \\
\hline Male gender & $38(54 \%)$ & $9(45 \%)$ & 0.61 \\
\hline Height in cm & $171.7(11.3)$ & $170.7(7.5)$ & 0.65 \\
\hline Weight in kg & $84.3(21.8)$ & $77.3(19.1)$ & 0.20 \\
\hline $\begin{array}{c}\text { Body Mass Index } \\
(\text { BMI) in kg/m }\end{array}$ & $28.4(6.1)$ & $26.3(5.5)$ & 0.18 \\
\hline Diabetes & $1(1 \%)$ & $6(30 \%)$ & $<0.001$ \\
\hline Smoking & 0 & $5(25 \%)$ & $<0.001$ \\
\hline Hypothyreodism & $9(13 \%)$ & $2(10 \%)$ & $>0.99$ \\
\hline
\end{tabular}

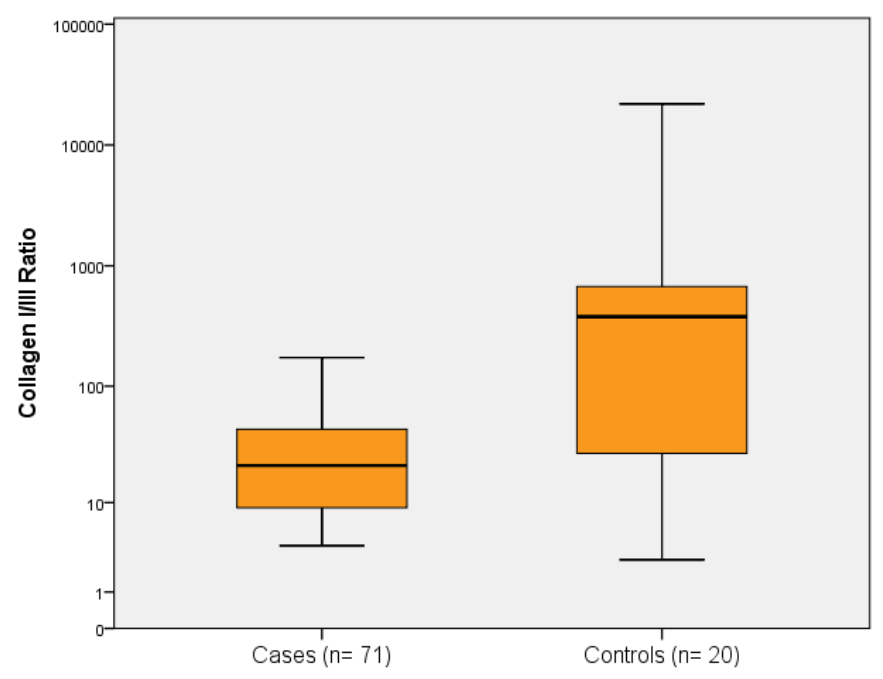

Figure 1. Comparison of collagen type I/III ratio between cases and controls 
Table 2. Comparison of collagen results between groups

\begin{tabular}{|c|c|c|c|}
\hline & Cases $(n=71)$ & Controls $(n=20)$ & $P$ value ( $t$ test) \\
\hline Collagen I & $\begin{array}{c}985,737 \pm 239,985 \\
\text { (Range } 595,484 \text { to } 1,604,827 \text { ) }\end{array}$ & $\begin{array}{c}2,136,504 \pm 669,870 \\
\text { (Range } 1,077,271 \text { to } 3,518,352 \text { ) }\end{array}$ & - \\
\hline LOG Collagen I & $5,98 \pm 0,10$ & $6,31 \pm 0,14$ & $<0,001$ \\
\hline Collagen III & $\begin{array}{c}69,397 \pm 56,700 \\
\text { (Range 5,524 to } 204,333 \text { ) }\end{array}$ & $\begin{array}{c}75,853 \pm 124,619 \\
\text { (Range } 148 \text { to } 399,245 \text { ) }\end{array}$ & - \\
\hline LOG Collagen III & $4,68 \pm 0,41$ & $4,00 \pm 1,03$ & 0,009 \\
\hline Collagen I/III ratio & $\begin{array}{c}32 \pm 32 \\
\text { (Range } 4 \text { to } 173 \text { ) }\end{array}$ & $\begin{array}{c}1992 \pm 5101 \\
\text { (Range } 3 \text { to } 21835 \text { ) }\end{array}$ & - \\
\hline Ratio of LOG Collagen I to LOG Collagen III & $1,31 \pm 0,43$ & $2,31 \pm 1,07$ & $<0,001$ \\
\hline
\end{tabular}

Table 3. Analysis of potentially confounding variables within the case group

\begin{tabular}{|c|c|c|c|}
\hline & Subgroup 1 & Subgroup 2 & $P$ value ( $t$ test) \\
\hline Age & $\geq 50$ years $(n=40)$ & $<50$ years $(\mathrm{n}=31)$ & \\
\hline LOG Collagen I & $6.00 \pm 0.10$ & $6.00 \pm 0.11$ & 0.28 \\
\hline LOG Collagen III & $4.68 \pm 0.42$ & $4.68 \pm 0.39$ & 0.99 \\
\hline $\begin{array}{l}\text { Ratio of LOG Collagen I to LOG } \\
\text { Collagen III }\end{array}$ & $1.32 \pm 0.43$ & $1.30 \pm 0.44$ & 0.79 \\
\hline Gender & Males $(n=38)$ & Females $(n=33)$ & - \\
\hline LOG Collagen I & $5.98 \pm 0.10$ & $5.98 \pm 0.11$ & 0.99 \\
\hline LOG Collagen III & $4.64 \pm 0.41$ & $4.72 \pm 0.41$ & 0.43 \\
\hline $\begin{array}{l}\text { Ratio of LOG Collagen I to LOG } \\
\text { Collagen III }\end{array}$ & $1.34 \pm 0.43$ & $1.26 \pm 0.44$ & 0.46 \\
\hline Body mass index & $\geq 30 \mathrm{~kg} / \mathrm{m}^{2}(\mathrm{n}=18)$ & $<30 \mathrm{~kg} / \mathrm{m}^{2}(\mathrm{n}=50)$ & \\
\hline LOG Collagen I & $5.99 \pm 0.09$ & $5.98 \pm 0.11$ & 0.91 \\
\hline LOG Collagen III & $4.43 \pm 0.40$ & $4.75 \pm 0.37$ & 0.003 \\
\hline $\begin{array}{l}\text { Ratio of LOG Collagen I to LOG } \\
\text { Collagen III }\end{array}$ & $1.56 \pm 0.42$ & $1.24 \pm 0.40$ & 0.005 \\
\hline
\end{tabular}

Table 4. Comparison of collagen results between groups after subdividing groups according to body mass index

\begin{tabular}{|c|c|c|}
\hline & Cases $(\mathbf{n}=\mathbf{7 1})$ & Controls $(\mathbf{n}=\mathbf{2 0})$ \\
\hline Non-obese subgroup (BMI $\left.<30 \mathrm{~kg} / \mathrm{m}^{2}\right)$ & $\mathrm{n}=50$ & $\mathrm{P}=15$ \\
\hline LOG Collagen I & $5.98 \pm 0.11$ & $6.31 \pm 0.15$ \\
\hline LOG Collagen III & $4.75 \pm 0.37$ & $4.12 \pm 1.00$ \\
\hline Ratio of LOG Collagen I to LOG Collagen III & $1.24 \pm 0.40$ & $2.19 \pm 1.03$ \\
\hline Obese subgroup (BMI $\left.\geq 30 \mathrm{~kg} / \mathrm{m}^{2}\right)$ & $\mathrm{n}=18$ & $\mathrm{n}=5$ \\
\hline LOG Collagen I & $5.99 \pm 0.09$ & 0.03 \\
\hline LOG Collagen III & $4.43 \pm 0.40$ & $3.65 \pm 1.17$ \\
\hline Ratio of LOG Collagen I to LOG Collagen III & $1.56 \pm 0.42$ & 2.001 \\
\hline
\end{tabular}

\section{Discussion}

The ratio of type I collagen to type III collagen has been studied in the disease processes related to the structural integrity of tissues [18, 22-25]. Some studies have demonstrated that a decrease in the collagen ratio plays a role in the recurrent inguinal hernias as well as aortic dissection [19,24]. Shaun et al evaluated the collagen content and type I/III collagen ratio in patients with diverticulitis versus a control group. They wanted to find out whether a lower type I to III collagen ration in younger patients may predispose these patients to the development of diverticulitis [15]. They demonstrated that diverticulitis in the younger patients is not associated with a lower type I/III collagen ratio. For them it appears that a decrease in collagen ratio of the colon in older patients is associated with an increase in type III collagen deposition [15]. Collagens are the most abundant macromolecules in the extracellular matrices and naturally occur in the cutaneous extracellular matrix [11]. Mutations in human collagen genes cause numerous connective tissue diseases and can disturb macromolecular skin architecture like in the Ehlers-Danlos syndrome [15]. Our data clearly demonstrate a decrease in the ration of type I to III collagen in hemorrhoidal tissue of patients suffering from enlarged hemorrhoids, thus indicating a reduced mechanical stability of the perivascular tissue and the anchoring connective tissue system. This goes hand in hand with the findings of Willis et al. [6] and the study of Nasseri et al. [26]: Regarding the still unknown process of pathophysiology of the hemorrhoidal disease we could not demonstrate any significant difference in our collective among different age groups. Although hemorrhoidal disease has been associated with older age in the general population perhaps due to genetic or hereditary factors patients with hemorrhoidal disease have a tendency for more rapid tissue degradation.

In the analysis of potentially modifying variables (Table 3 ) in our data, gender showed no association with collagen fibers. However, obese patients had a significantly higher collagen type I/III ratio as compared to patients without obesity. Therefore, analyses were repeated for both subgroups of obese and non-obese patients and the results were the same. There are no data in international literature evaluating the influence of obesity or the influence of body weight on the development of hemorrhodial disease. In our subgroup analyses the non-obese cases $(\mathrm{BMI}<30)$ showed a significant lower ratio of collagen I/III as the controls and the obese cases (BMI $\geq 30$ ) had also a significant lower ratio as the controls. This could indicate that obesity is an independent variable in the pathophysiology of hemorrhoidal disease. Our hypothesis that collagen metabolism might play a role in the etiology of hemorrhoidal disease is in line with Stelzner's 
hypothesis of hemorrhoidal development: The physiological aging process (degradation of elastin) in combination with a reduction of the tensile strength of the collagenous components causes a loss of elasticity. This could lead to an outflow obstruction and a pressure increase in the arteriovenous glomerula with vascular dilatation. Causing a destruction of the collagenous attachment of the vascular padding and resulting in descendation of the corpus cavernosum recti below the dentate line [6]. Epidemiological data show an association with herniae and genitourinary prolapse [6] that might be caused by individual connective tissue abnormalities.

We can conclude, in our study we found a significant reduction of the collagenous ratio I/III in the hemorrhoidal tissue in patients with hemorrhoidal disease in comparison to controls. Discussing the findings on the background of international literature and taking in consideration, that the connective tissue must be regarded as a highly dynamic and complex system with permanent cell turnover and remodeling of the extracellular matrix, the pathophysiological process of hemorrhoidal disease should be seen in association with this.

Nevertheless, it remains still unclear, whether the changes of collagen formation in hemorrhoidal tissue are caused by exogenous factors or hereditary reasons. Further research has to be done on collagenous metabolism and the influence of social and cultural factors facing the pathophysiology of hemorrhoidal disease.

\section{Compliance with Ethical Standards}

Corresponding author Mike Ralf Langenbach declares that he has no conflict of interest. Co-author Roman Lisovets declares that he has no conflict of interest. Co-author David Varga-Szabo declares that he has no conflict of interest. Co-author Lars Boenicke declares that he has no conflict of interest.

All procedures performed in the study were in accordance with ethical standards of the institutional and national research committee and with the 1964 Helsinki declaration and its later amendments.

\section{Consent}

Informed consent was obtained from all individual participants included in the study.

\section{Conflicts of Interest}

There is no conflict of interest to disclose for all authors.

\section{Acknowledgement}

Mike Ralf Langenbach (study concept and design; acquisition of data; analysis and interpretation of data; drafting of the manuscript)

Roman Lisovets (acquisition of data; analysis and interpretation of data; drafting of the manuscript)

David Varga-Szabo (critical revision of the manuscript for important intellectual content; statistical analysis)

Lars Bönicke (critical revision of the manuscript for important intellectual content; statistical analysis)

\section{References}

1. Bruch HP, Roblick UJ (2001) [Pathophysiology of hemorrhoids]. Chirurg 72: 656-659. [Crossref]

2. Stelzner F, Staubsand J (1962) Das Corpus cavernosum recti - morphologische Grundlage der inneren Hämorrhoiden. Langenbecks Arch Chir 229: 302-12.

3. Johanson JF, Sonnenberg A (1990) The prevalence of hemorrhoids and chronic constipation. An epidemiologic study. Gastroenterology 98: 380-386. [Crossref]
4. Haas PA, Haas GP, Schmaltz S, Fox TA Jr (1983) The prevalence of hemorrhoids. Dis Colon Rectum 26: 435-439. [Crossref]

5. Stelzner F (1998) Chirurgie an den Viszeralen Abschlusssystemen. Thieme, Stuttgart.

6. Willis S, Junge K, Ebrahimi R, Prescher A, Schumpelick V (2010) Haemorrhoids - a collagen disease? Colorectal Dis 12: 1249-1253. [Crossref]

7. Holbrook KA, Byers PH (1982) Structural abnormalities in the dermal collagen and elastic matrix from the skin of patients with inherited connective tissue disorders. $J$ Invest Dermatol 79: 7-16.

8. Pepin MG, Byers PH (1999 updated 2011) Ehlers-Danlos Syndrome Type IV. In: Pagon RA, Adam MP, et al (eds.) GeneReviewsTM. Seattle (WA): University of Washington, Seattle.

9. Hamel BC, Pals G, Engels CH, van den Akker E, Boers GH, et al. (1998) Ehlers-Danlos syndrome and type III collagen abnormalities: a variable clinical spectrum. Clin Genet 53: 440-446.

10. Chiodo AA, Sillence DO, Cole WG, Bateman JF (1995) Abnormal type III collagen produced by an exon-17-skipping mutation of the COL3A1 gene in Ehlers-Danlos syndrome type IV is not incorporated into the extracellular matrix. Biochem $J 311$ : 939-943. [Crossref]

11. Lattouf R, Younes R, Lutomski D, Naaman N, Godeau G, et al. (2014) Picrosirius red staining: A useful tool to appraise collagen networks in normal and pathological tissues. J Histochem Cytochem 62: 751-758.

12. Friedman DW, Boyd CD, Norton P, Greco RS, Boyarsky AH, et al. (1993) Increases in type III collagen gene expression and protein synthesis in patients with inguinal hernias. Ann Surg 218: 754-760. [Crossref]

13. Schäffer M, Becker HD (1999) [Immune regulation of wound healing]. Chirurg 70 897-908. [Crossref]

14. Hurme T, Kalimo H, Sandberg M, Lehto M, Vuorio E (1991) Localization of type I and III collagen and fibronectin production in injured gastrocnemius muscle. Lab Invest 64 : 76-84. [Crossref]

15. Brown SR, Cleveland EM, Deeken CR, Huitron SS, Aluka KJ, et al. (2017) Type I/type III collagen ratio associated with diverticulitis of the colon in young patients. $J$ Surg Res 207: 229-234. [Crossref]

16. Stadelmann WK, Digenis AG, Tobin GR (1998) Physiology and healing dynamics of chronic cutaneous wounds. Am J Surg 176: 26S-38S. [Crossref]

17. Stumpf M, Cao W, Klinge U, Klosterhalfen B, Kasperk R, et al. (2001) Increased distribution of collagen type III and reduced expression of matrix metalloproteinase 1 in patients with diverticular disease. Int J Colorectal Dis 16: 271-275.

18. Wess L, Eastwood MA, Wess TJ, Busuttil A, Miller A, et al. (1995) Cross linking of collagen is increased in colonic diverticulosis. Gut 37: 91-94. [Crossref]

19. Ouriel K, Schwartz SI (1983) Diverticular disease in the young patient. Surg Gynecol Obstet 156: 1-5. [Crossref]

20. Thomson WH (1975) The nature of haemorrhoids. Br J Surg 62: 542-552. [Crossref]

21. Lierse W (1989) [Anatomy and pathophysiology of hemorrhoids]. Langenbecks Arch Chir Suppl II Verh Dtsch Ges Chir. [Crossref]

22. Junge K, Klinge U, Rosch R, Mertens PR, Kirch J, et al. (2004) Decreased collagen type $\mathrm{I} / \mathrm{III}$ ratio in patients with recurring hernia after implantation of alloplastic prostheses. Langenbecks Arch Surg 389: 17-22. [Crossref]

23. Klinge U, Si ZY, Zheng H, Schumpelick V, Bhardwaj RS, et al. (2001) Collagen I/III and matrix metalloproteinases (MMP) 1 and 13 in the fascia of patients with incisional hernias. J Invest Surg 14: 47-54. [Crossref]

24. Klinge U, Si ZY, Zheng H, Schumpelick V, Bhardwaj RS, et al. (2000) Abnormal collagen I to III distribution in the skin of patients with incisional hernia. Eur Surg Res 32: 43-48. [Crossref]

25. Anderson DW, Edwards TK, Ricketts MH, Kuivaniemi H, Tromp G, et al. (1996) Multiple defects in type III collagen synthesis are associated with the pathogenesis of abdominal aortic aneurysms. Ann N Y Acad Sci 800: 216-228. [Crossref]

26. Nasseri YY, Krott E, Van Groningen KM, Berho M, Osborne MC, et al. (2015) Abnormalities in collagen composition may contribute to the pathogenesis of hemorrhoids: morphometric analysis. Tech Coloproctol 19: 83-87.

Copyright: (C2018 Langenbach MR. This is an open-access article distributed under the terms of the Creative Commons Attribution License, which permits unrestricted use, distribution, and reproduction in any medium, provided the original author and source are credited. 